\title{
Autonomía y creación de capacidades y emociones en la familia desde la perspectiva de la humanidad y la cultura
}

Francisco AlONSO CHICA CAÑAS*

\section{Introducción}

Este escrito es el resultado de una investigación que se realizó en la Universidad Santo Tomás, en la que se da continuidad al tópico de autonomía relacionado con la creación de capacidades y emociones de la familia en aras de cultivar el humanismo a partir del contexto de la cultura. Se habla de autonomía como una pieza clave para atender los asuntos educativos. Sin embargo, el primer referente de desarrollo se centra en el núcleo familiar, en el cual se gesta el gobierno de sí mismo para abordar relaciones emocionales y racionales, para afrontar el

* Licenciado en Educación, Filosofía y Letras, magíster en Educación y Filosofía Latinoamericana, especialista en Gerencia de Instituciones de Educación Superior y Posdoctorado en Educación, Ciencias Sociales e Interculturalidad de la Universidad Santo Tomás. Magíster en Docencia Universitaria de la Universidad de La Salle. Especialista en Pedagogía para el Desarrollo del Aprendizaje Autónomo de la Universidad Nacional Abierta y a Distancia. Doctor en Currículum, Profesorado e Instituciones Educativas de la Universidad de Granada. Actualmente forma parte de los grupos de investigación Fray Saturnino Gutiérrez, O. P. y Filosofía de la Educación en Colombia y América Latina de la Universidad Santo Tomás. 
proyecto de vida personal, inmerso en una sociedad caótica y anárquica que socava los intereses de la familia, dejando como único salvavidas el humanismo, que es el medio para transformar prácticas culturales nocivas para la dignidad de la persona.

La familia atraviesa por un tiempo de crisis en el que las costumbres, los comportamientos, las actitudes y los valores han cambiado por el influjo de la ciencia y la tecnología, los medios de comunicación y el internet, la política y la economía, el consumo y la oferta, los mercados y la producción, las tradiciones y las ideologías, las guerras y las religiones, la vida y la muerte, entre otras causas; esta serie de fenómenos sociales impacta de forma decisiva en el hacer y ser del hombre actual. Por tanto, es importante analizar cómo, a partir de la autonomía, se pueden crear capacidades y emociones en la familia, con un enfoque de la humanidad y la cultura basado en el respeto a la dignidad humana y el buen ejercicio de la libertad. Este enfoque daría pie para afrontar los desafíos de una sociedad líquida que experimenta una fuerte revolución cultural, en la que se impone el consumismo y el mundo de la información, y que altera los valores de una ética universal e impone una ética relativa; una sociedad banal que se mueve entre lo contingente y lo inmediato, la violencia y la muerte, la guerra y la destrucción.

Urge pensar y obrar en torno a la creación de capacidades y emociones en la familia, para afrontar con conciencia los retos de un desafío secular que deshumaniza. El propósito es cultivar la humanidad alrededor del diálogo, la escucha, la tolerancia, la libertad y la sensibilidad hacia lo que sucede al otro. Una de las grandes capacidades es el amor, porque se aprende a cuidar, a tolerar, a respetar, a servir, a perdonar, a entregar lo mejor de sí mismo con base en una iniciativa amorosa que persigue el bien común y no el bien particular. La capacidad amorosa permite crear nuevas capacidades cognitivas, emocionales y evaluativas que van a incidir en los hábitos de la familia para que impere el amor filial, el cuidado y la protección de la prole, para que adquiera relevancia el aprendizaje para ser mejores personas y la iniciativa para hacer siempre el bien. Esta capacidad amorosa está a prueba ante una sociedad que se desmorona por su propio ingenio y creatividad, cuyo afán depredador no 
encuentra límite en la riqueza, el poder, el confort, el utilitarismo, el pragmatismo, el bienestar, en ideales políticos beligerantes y placeres tentadores provenientes del vandalismo, la droga, el dinero fácil, por enumerar algunas de las tantas situaciones problemáticas que se viven actualmente.

Además, la familia tiene que crear capacidades de afiliación emocional para cultivar la humanidad, en las que se aprecie la reciprocidad e interés por la situación que vive la otra persona. Así, la ética del cuidado asume un papel protagónico, porque se debe saber lo que hacen los congéneres dentro y fuera de la casa. Esto significa rodearlos con atención para orientarlos con un sentido ético de la vida, lo que requiere un trabajo solidario y en equipo que deje a un lado el egoísmo y la envidia, para ocuparse de lo que hacen bien o mal las personas con las que se convive. No se puede ser indiferente ante las situaciones críticas que hieren la familia en el ámbito de las virtudes, los valores, las tradiciones, los hábitos y los espacios sociales. Promover la capacidad de afiliación es trabajar en pro de la inteligencia emocional y de la empatía, las cuales conducen a la felicidad del hombre, una felicidad que requiere tolerancia y respeto, como también ayuda recíproca: un yo que es un tú.

El acceso a las capacidades internas para el desarrollo de la autonomía es importante tanto para la realización de los sueños personales, como para la capacidad de autoestima y de automotivación; la conciencia de sí mismo, para deliberar sobre lo que se hace, para pensar y reflexionar en torno al individuo y la colectividad; el poseer una inteligencia intrapersonal y el amor incondicional permite valorar lo que hace cada miembro de la familia a sabiendas de las imperfecciones y las virtudes, de los anhelos y la desesperanza. Las capacidades internas son el motor que impulsa a abrazar el horizonte de la vida, sea en medio de la pobreza o la opulencia; sin embargo, se requiere una participación activa del Estado, las empresas, las instituciones y la sociedad, para hacer realidad el sueño de miles o de millones de familias que viven privadas de la educación, la salud, la vivienda o el trabajo, por describir algunas de las tantas situaciones complejas que viven las sociedades en América Latina. También, se necesita voluntad política para asumir una conciencia social de 
leyes y normas que cambien la vida de hombres, mujeres, niños y jóvenes, para participar en proyectos que dignifiquen a la persona y mejoren la calidad de vida.

Por otra parte, para crear capacidades y emociones humanas en la familia, se tienen que incorporar las capacidades secundarias, al tiempo que se atiende la demanda de las capacidades centrales, internas y de afiliación. En otras palabras, hay una pluralidad de deseos, de proyectos y de inversiones de capital cultural, que retumban en la vida de la familia y que implican búsquedas en torno al arte y la estética, el deporte, la música, la recreación y el descanso, el estudio, la política, el trabajo social comunitario, el cuidado del medio ambiente y los recursos naturales, la atención a las personas con discapacidad, y minusválidos, el cooperativismo, el profesionalizarse, por nombrar solo algunos de un sinnúmero de proyectos que embargan a familias paupérrimas, emergentes, ascendentes, disfuncionales o destruidas por la violencia y la muerte. Si se desea transformar el mundo, es necesario que la familia sea el centro de atención de los políticos, de la economía, de la inversión de países con potencial económico, de la religión y la iglesia, la ciencia y la tecnología, los empresarios y los industriales, la cultura y el arte, la escuela y la universidad. Es decir, más que pensar en un proyecto neoliberal y de globalización de carácter económico, se debería pensar en un proyecto de vida para la familia, sin importar raza, sexo, edad y género, para cultivar la humanidad en una época de crisis social.

\section{Reflexión en torno a una cultura de la paz}

El tema de la paz se convirtió en prioritario para la agenda del Estado colombiano, lo que implica pensar en la familia como la base de los proyectos venideros para trabajar en el posconflicto. Por tal razón, no se puede hablar de paz si el gobierno de turno, las instituciones y la sociedad, no son capaces de emprender proyectos que posibiliten crear en las familias capacidades relacionadas con la autonomía, para formarse como persona en medio de un entorno adverso y enrarecido por intereses políticos, ideológicos y económicos. 
Las familias están marginadas y desechadas por circunstancias como la falta de oportunidades en el mundo laboral, la imposibilidad de acceder a un sistema educativo, por no disponer de los servicios básicos y secundarios, por la pérdida de un horizonte para crecer dignamente, como resultado de una sociedad secularizada, capitalista, neoliberal y deshumanizante. El fenómeno de las familias que forman parte de la sociedad del descarte, en parte obedece a la falta de oportunidades de ascenso; garantizar esas oportunidades contribuiría a resolver el problema del posconflicto y a sentar las bases de una paz duradera, en la que el Estado, las instituciones y la sociedad civil puedan crear capacidades para minimizar los efectos de la desigualdad, a partir del apoyo al núcleo familiar en cuanto a las circunstancias económicas, sociales, culturales y educativas, para una formación integral humanista.

Por otro lado, sin embargo, las ofertas de un mundo líquido arrastran a determinadas familias de estratos altos por el camino de la riqueza y el poder, el sexo, la droga y lo que ofrece una sociedad capitalista a través de los medios de comunicación. Entonces, puede decirse que la familia está en crisis, porque la paz se cultiva en un núcleo familiar que disponga de los recursos económicos para sobrevivir, pero también que experimente el amor y el afecto de los seres queridos para forjar lazos de solidaridad, reciprocidad, sana convivencia, respeto, entrega y servicio al otro. La paz es un proyecto para cultivar el humanismo en el entorno familiar, lo cual es muy complicado en una sociedad que pregona la igualdad en medio de situaciones de desigualdad, que produce un abismo cada vez mayor. La familia está sucumbiendo a los intereses de un mundo secularizado y plagado de tecnología, de modas, de razonamientos instrumentales y de la oferta y la demanda del mercado.

La paz se conquista en el seno de la familia, lo que requiere de un proyecto de bienestar educativo, social, cultural, político y productivo. Todo ello se enmarca en la creación de capacidades de autonomía para amar a los integrantes de la familia, sea en circunstancias de adversidad o prosperidad, fenómeno que en la vida cotidiana se presenta con aristas: pobreza, miseria, prostitución, marginalidad, degradación, entre otros. Estas circunstancias exigen del individuo capacidades de autonomía para motivarse, poseer una alta autoestima, tomar la iniciativa 
para emprender acciones por sí mismo y por los demás y, sobre todo, tomar conciencia del potencial que posee la familia para convertirse en la piedra angular del cambio, con el que se lograrían las metas del proyecto de vida personal. La negación de la humanidad se combate a través de la humanidad; es decir, se debe partir del ámbito de los valores para luchar contra la alienación y cosificación del ser humano.

\section{Antecedentes del problema de investigación}

La familia ha sufrido una serie de cambios que le impone el mundo cultural, lo que implica comprender las dinámicas por las que esta atraviesa en el siglo Xxi. Para ello, Solís (2004) propone conceptualizar la familia en el entorno cultural, teniendo en cuenta los referentes de la Sociología, la antropología y la historia, según los cuales la modernidad y la posmodernidad han impactado en la conducta y el comportamiento, lo que se refleja en una sociedad utilitarista y de consumo. Adicionalmente, plantea que la desintegración de la unidad familiar propicia la soledad del hombre y la mujer, y se pierde el sentido de crear una familia que se preocupe por los hijos. Por otra parte, aborda la permanencia de la tradición en asuntos como el machismo, en comportamientos feudales e irreflexivos que no valoran a los integrantes de la familia, en la medida en que la cultura se convierte en un medio de legalización de prácticas de orden físico y emocional que avalan la hegemonía masculina. Finalmente, afirma que se deben tomar en cuenta los vacíos del saber social para superar viejos paradigmas y recrear unos nuevos que conceptualicen el papel de la familia en el siglo XXI.

Unicef (2003) recopila una serie de investigaciones centradas en las nuevas formas de la familia en el ámbito nacional e internacional, en las que se debate sobre las transformaciones de la familia occidental en el mundo contemporáneo. Se estudia allí cómo la familia nuclear cede a diversas formas de vivencias familiares. Asimismo, se estudia la disolución de las familias y la vinculación de la mujer al campo laboral. Ahora, al lado de la familia nuclear, aparecen otras formas de familias, las monoparentales o las ensambladas. Es necesario resaltar que 
la desintegración de la familia ha contribuido al fortalecimiento de la ilegalidad a partir de una ética relativa. También, en América Latina las investigaciones sobre la familia son escasas y se rigen por datos que brindan los censos y estadísticas, que no consideran la problemática de la diversidad de la familia. Sin embargo, Uruguay emprendió un proyecto sobre la familia tomando como referente familias monoparentales, que desemboca en consideraciones sobre el desempeño social de la mujer en Montevideo y el área metropolitana. A pesar de la escasa información hay avances al respecto, por ejemplo, en septiembre de 2002, Unicef organizó el seminario denominado "Transformaciones familiares, desempeños sociales y derechos", que contó con la participación de países como Estados Unidos, Francia, Inglaterra, Argentina y Brasil.

Por su parte, Rovichaux (2007) introduce la lógica cultural en la que se fortalece la familia nuclear desde la perspectiva europea, y que olvida las diferentes formas sociales de las etnias de América Latina, fenómeno que ha sido presenciado también con las prácticas de los conquistadores y la aculturación fraguada por los dominadores, y ha generado una tendencia homogeneizadora que oculta las formas y concepción de familia propias, genuinas, de las etnias. No obstante, las tradiciones culturales se constituyen en prácticas asumidas por los grupos étnicos de América Latina, quienes establecen las formas de parentesco y de redes respondiendo a una concepción del pensamiento precolombino y caribeño, que muestra la complejidad de sus sistemas familiares. Lo anterior apunta a que existe una morfología estructurante como resultado de productos culturales, hábitos, comportamientos y prácticas aprendidas en las etnias, que riñen con los postulados de la conquista, de la era industrial y del siglo Xxi. Es muy importante entender que existe una tradición cultural familiar estructurante y que, con la aparición del mundo secularizado, se introducen formas aculturales que se instalan en la Torre de Babel de la sociedad contemporánea. Esto complejiza el problema de la concepción de familia en un mundo caótico y líquido que adquiere nuevas formas, moldeadas por los medios de comunicación, la cibercultura y el imperativo de cambio basado en una ética relativa o posmoderna.

Pachón (2007) se expresa acerca de la sacralización que se hace de la familia, viendo en ella una imagen ideal que no se contamina de los 
conflictos; sin embargo, por la diversidad geográfica y cultural, aparecen múltiples conceptos estructurantes de la familia en Colombia que pasan por la etapa prehispánica, colonial, republicana y del siglo xx, afectando las prácticas cotidianas y el funcionamiento personal y grupal. Entonces, según los resultados de los investigadores, la familia de principios de siglo se caracteriza como "familia patriarcal, extensa y prolífica [...], mientras que en los sectores populares predominaba la familia nuclear, esta familia extensa y patriarcal era común en los estratos medios y altos, tanto urbanos como rurales" (p. 147), especialmente en aquellos lugares en los que se instaló la religión católica. Ahora, el modelo ideal de familia se comparaba con la Sagrada Familia, que planteaba un determinado estilo de comportamiento. A principios del siglo xx surgió el problema de ilegitimidad de los niños nacidos fuera del sistema religioso (que alcanzó cifras alarmantes en Bogotá y la Costa Atlántica); los hijos naturales fueron rechazados por algunos sectores educativos, por el Ejército y, en los seminarios, estaban vetados para ejercer el sacerdocio. A pesar de la resistencia respecto a las nuevas formas culturales de la familia, estas se impusieron en la clase media y alta. Apareció entonces el uso de anticonceptivos, que no se dio igual en las familias de estratos bajos, que mantenían altas tasas de natalidad. Esto conllevó que en el país se abriera el debate sobre el rol de la mujer, el bienestar de los hijos, los problemas conyugales, la satisfacción de las necesidades de los padres y su búsqueda de la felicidad, la posición de la Iglesia frente a los nuevos retos de la familia, la inestabilidad en las familias proletarias, la incidencia del alcohol y demás implicaciones de las relaciones familiares.

Calvo (1995) realizó una investigación sobre la familia en Colombia, un estado del arte entre 1980-1984 publicado por el Instituto Colombiano de Bienestar Familiar. Allí se analizan los problemas de la familia en el país, y se compilan evidencias que provienen de las facultades de sociología, psicología, enfermería y antropología, entre otras entidades. En esta investigación se caracterizan las familias por regiones culturales (urbana o rural), según las creencias, prácticas de crianza, estilos de vida de las familias nucleares y extensas. También estudia las familias con problemas de "alcoholismo, la violencia carnal, la histeria, la drogadicción, la farmacodependencia, la sordera, la 
delincuencia juvenil y la reclusión en centros carcelarios" (p. 38), y su actitud para enfrentarlos. Igualmente, se estudia la vinculación de la mujer al mundo laboral respecto a la crisis que genera en la familia. Por lo demás, el análisis trata sobre la desintegración familiar, las nuevas formas de familia, las relaciones entre madre, padre e hijo. Por tanto, la investigación proporciona información valiosa para que se conciba una familia que pueda atender las demandas de sus integrantes, específicamente aquellas relacionadas con el papel de la mujer en el mundo contemporáneo. Esto insta a que se formulen programas educativos dirigidos al hombre y, en especial, a la mujer.

De lo anterior, se evidencia la necesidad de seguir investigando sobre la familia, no tanto para realizar diagnósticos acerca de las diversas aristas del problema, sino para crear capacidades y emociones entre sus integrantes en el aspecto humanista y cultural. Ello implica ver el problema de investigación desde el papel que desempeña la autonomía en la familia, para propiciar emociones que cuenten con una base sólida en el humanismo y la cultura, ya sea como limitante, o detonante de acciones que involucran a la persona, la sociedad, las instituciones y el Estado. Con esta base se podrán crear capacidades y lineamientos en el campo de la política y la economía, con el ánimo de mejorar la calidad de vida de las familias colombianas, con un sentido del potencial que posee el hombre para hacer cosas y llegar a ser mejor persona en el ámbito de la dignidad.

El desarrollo de la autonomía en la familia es el germen de la creatividad, de la indagación, la exploración, en el proceso de formación del espíritu científico, y es la clave para una cultura de identidad cuya referencia sea el cultivo de la humanidad. Sin embargo, lo que se aprecia es una total heteronomía en los miembros de la familia, una sociedad secularizada, bombardeada por los medios de comunicación, por el auge de la violencia y la muerte, por la moda convertida en una forma de vida, por la droga como un merodeador que contamina el cuerpo y la mente, también por el producto de culturas foráneas del mundo globalizado que altera los lazos amorosos y afectivos, y por los intereses que pregona la sociedad secularizada. Por esta razón, existe la sensación de que la autonomía no es fundamental para el desarrollo humano y de la cultura, para cultivar capacidades 
emocionales que construyan pilares para la vida, capacidades que abarquen los sentimientos amorosos, la solidaridad, reciprocidad, el compromiso y acciones concretas para el cuidado de la familia, que es la célula más importante de la sociedad.

\section{Problema de investigación}

Como se ha mencionado, la familia experimenta una crisis en cuanto al estilo de vida, comportamiento, creencias, actitudes, valores, por la aparición de nuevas modalidades de familia, la aculturación occidental, el impacto de los medios de comunicación, el afianzamiento del mundo secularizado, entre otros factores. Estos problemas, que forman parte del mundo contemporáneo, han minado el núcleo familiar, forzando a sus integrantes a un mundo caótico que diluye las relaciones amorosas, económicas y sociales, a cuestiones inmediatistas, propias del laicismo, la ciencia, la tecnología, la política, la economía y la comunicación. Esto indica que la familia se encuentra en el escenario del mundo líquido, de formas y volúmenes tan variados que impiden captar la esencia de las emociones con las que desempeñarse en interacciones sociales (comunicativas, axiológicas, educativas y de emprendimiento), para vivir una vida con calidad y de respeto por la dignidad del otro, en escenarios estructurantes de la cultura. De ahí que Bauman (2013) se plantea la pregunta del estilo de vida actual en "la 'modernidad líquida', una sociedad de consumidores individualizada y sin regulaciones, formada en un escenario crecientemente globalizado" (p. 35). Es decir, una sociedad que perdió la capacidad de autorregularse frente a las demandas de un mundo gobernado por el imperio de la economía, la ciencia y la tecnología, frente a las demandas políticas e ideológicas y la afloración de una ética de la relatividad que afecta directa e indirectamente a la familia.

Un gran detonante de la fragmentación de la familia tiene que ver con la pérdida del humanismo, que propicia el surgimiento de emociones de apatía, indiferencia, violencia, que a su vez ocasionan hechos como el feminicidio, el abuso sexual de los niños y niñas, el maltrato en general a la mujer y los infantes, la pérdida del respeto de los 
hijos a los padres, la ausencia de valores, el desconocimiento de las capacidades de la mujer, el descuido de la formación de la niñez y la adolescencia, en fin, pésimas interacciones interpersonales en el núcleo familiar. Valores relacionados con la comprensión, la vivencia del amor, la tolerancia, la justicia, la equidad, la igualdad, la solidaridad, la convivencia social, la moral cívica, la autonomía moral, la conciencia moral, los derechos humanos y demás, se han perdido en la sociedad y se han impuesto emociones del mundo de la oferta, del consumo, de la banalidad, de la acumulación de bienes, de odios y venganzas, de desconocimiento de la armonía social, incidiendo en la dinámica social de la familia, que termina deshumanizada y carente de valores éticos para afrontar la avalancha de la sociedad que afinca sus anhelos en el materialismo. Se puede generalizar que el mundo contemporáneo requiere trabajar en torno a "la construcción de una teoría de la justicia social básica que añade otras nociones en el proceso (como las de la dignidad humana, nivel de umbral y liberalismo político)" (Nussbaum, 2012, p. 39). Esto significa que el abordaje del humanismo es una cuestión de la política que afecta al ciudadano y de paso a la familia, lo que también implica humanizar los ámbitos de la economía, la ciencia y la tecnología.

Educar al ciudadano involucra a la familia, en el entendido de que esta capacita al individuo para tener oportunidades de crecer en un mundo de asimetría educativa, especialmente cuando se trata de los países de América Latina, cuyo grueso de población no puede acceder a una formación de educación superior. Por tal razón, la autonomía en la familia apunta, en el terreno educativo, a gestar emociones sanas de entendimiento y de integración social, además de que traza un camino para desarrollar capacidades que le permitan al individuo tener un buen empleo o trabajo, una vivienda, acceso a salud de calidad, a una alimentación sana, disponer de espacios recreativos, tener participación en el mundo cultural y artístico, aportar al mundo de la ciencia y la tecnología, formar un criterio para la toma de decisiones políticas, en fin, a partir de la autonomía se abre un mundo de posibilidades que convierten al individuo en un interlocutor cognitivo e ilustrado, en un mundo que exige una mayor formación intelectual y científica. Asimismo, desde la familia se requieren ejercicios políticos 
que refuercen su rol formativo, si se quiere que sus integrantes hagan parte de un mundo democrático que garantice la educación.

Se necesita de grandes reformas muy creativas por parte del Estado, las instituciones educativas y la sociedad, que ayuden al individuo a emprender el camino de la ilustración, para contrarrestar la tendencia hacia el analfabetismo, la ignorancia, el conocimiento vulgar, las ofertas atractivas de un mundo de apariencia y la postura acrítica sobre la vida. Por tal motivo, "Dewey siempre sostuvo que en una buena escuela, los alumnos aprenden a ser ciudadanos realizando proyectos en común con sus compañeros y resolviéndolos en conjunto, con un espíritu respetuoso, pero, al mismo tiempo, crítico" (Nussbaum, 2011, p. 97). En otras palabras, la escuela es para la familia un horizonte de conciencia profesional, una conciencia para proyectarse dignamente en la vida, para asumir, por iniciativa propia, la formación educativa de sí mismo y de la prole y, a fin de cuentas, de una sociedad que sea bondadosa con la familia y que asuma proyectos en comunión con cada integrante de la célula social.

Los medios de comunicación crean ilusiones en la familia al presentar modelos y prototipos de héroes y antihéroes, al generar dependencia hacia un estilo de vida imaginada, vandálica, con referentes en el mundo de la drogadicción, del mercado del sexo, del dinero, de las luchas por el poder en medio de ideologías políticas que pretenden ser abanderadas del sentimiento del pueblo, entre otras cuestiones. Todos estos referentes tienen audiencia en cada integrante de la familia, que los puede asumir como un camino ideal, especialmente en aquellas familias paupérrimas o marginadas que, alienadas por la pobreza, el hambre, la pérdida de valores, la carencia de autoestima y dignidad, descubren allí un camino a seguir. También, para las familias de clase media, que son un poco más pudientes por el ascenso social, existe la tentación de la riqueza, el consumo, la inmersión en el mundo de la oferta y la demanda del mercado, lo que genera en ellos la percepción de que la educación es un medio para abrir las puertas del bienestar económico, todo por el impacto de los medios de comunicación en la mente de las familias emergentes. Las familias con un nivel económico alto también se dejan seducir por las bondades del capitalismo y de la cultura de la comunicación, la 
ciencia y la tecnología, que imponen una vida materialista que minimiza la autonomía de la familia al suplir una experiencia de amor con bienes materiales.

Sobre las implicaciones del libre juego de oferta y demanda que se impone, Bauman advierte consecuencias desfavorables, según él:

Es preferible que sean productos de consumo único, que se puedan desechar y reemplazar con rapidez, de tal manera que el espacio en que uno vive no vaya a convertirse en un confuso basurero, una vez codiciado los objetos que hoy son objeto de admiración y dejen de estar moda. Los clientes, confundidos por la aturdidora variedad de ofertas y el vertiginoso ritmo con el que cambian, ya no pueden confiar en su capacidad para aprender y memorizar. (Bauman, 2013, pp. 46-47)

La autonomía y las emociones para crear capacidades desde la familia se ven obstaculizadas por una diversidad de racionalidades, estructuras lógicas, modas y paradigmas que impone el mercado del mundo global, el cual penetra a través de los medios de comunicación para moldear las necesidades de las personas en todos los ámbitos de su vida. No se puede dudar de que las conductas y los comportamientos en el seno de la familia están atomizados por el internet, la televisión, la radio, el cine y el mundo digital, y que estos crean nuevas necesidades a través de la imagen, el símbolo y el signo. Estas nuevas necesidades reconfiguran el contexto de la familia, sus relaciones de afecto y de amor, los modos de percibir la sexualidad y de relacionarse con los demás; aparece entonces la violencia como producto de luchas enrarecidas en la política mundial, gravitando entre ideologías de centro, derecha e izquierda, y el cúmulo de información sobre diversos aspectos de la vida del individuo. La tecnología se instaló en el seno de los hogares; en algunos casos, se convierte en una terapia o forma de vida que alimenta la desesperanza y la esperanza, la frustración y el éxito, los amores y los desamores, los ídolos y antiídolos, la depresión y la alegría, la bondad y la violencia, la imitación y la identidad, la moda y la autenticidad, o sea, 
la dramaturgia del mundo de los medios de comunicación adquiere dimensiones insospechadas en la vida de la familia citadina y rural, en sus emociones, de tal manera que afecta a cada integrante de la familia. Esto, como se dijo, requiere crear capacidades emocionales basadas en el amor para contrarrestar las demandas materiales de la vida. Por tanto, "los hechos culturales podían interpretarse a la luz de un fondo de hechos no culturales sin disolverlos en ese fondo ni disolver el fondo de los hechos mismos" (Geertz, 2006, p. 46). Esto significa que, en medio del caos cultural, la familia ocupa un lugar estratificado en la sociedad, en que aparecen niveles ocultos y visibles a los ojos de los individuos.

La investigación utilizó el método cualitativo, que implica el manejo de varias etapas, como la exploración de la situación problema, el uso de métodos para la recolección de datos, la organización e interpretación de la información cualitativa, la interpretación de los resultados y la conceptualización inductiva o inducción analítica, todo relacionado, por supuesto, con la autonomía y el desarrollo humano en la familia, en el ámbito de la cultura. Bonilla y Rodríguez (2000) sostienen la necesidad de delimitar el estudio para saber qué se puede hacer, plantear preguntas analíticas, planear reuniones para recopilar la información, realizar una reseña sistemática de los datos, revisar continuamente las observaciones para identificar comportamientos y confrontar los datos que proporcionen los informantes, y elaborar un panorama de los procesos que se van ajustando en la investigación.

Para esta investigación se contó con la participación de veinte estudiantes de la Licenciatura en Filosofía y Lengua Castellana, quienes mediante la entrevista de grupo focalizado manifestaron su percepción sobre cómo la autonomía posibilita crear capacidades y emociones en la familia, cómo puede proyectarse como un ideal de gobierno que implique el Estado, las instituciones y la sociedad, para generar transformaciones en una sociedad caótica que evoluciona en el ámbito cultural. Su participación posibilitó plantear las siguientes preguntas:

- ¿Qué papel desempeña la autonomía en la familia para afrontar los desafíos del mundo contemporáneo en cuanto a la política, 
la ciencia, la tecnología, la educación, el emprendimiento, el arte, la estética y otros aspectos?

- ¿Cómo la autonomía favorece la creación de capacidades y emociones en la familia desde la perspectiva de la humanidad y la cultura?

- ¿Cómo la capacidad del amor se constituye en la capacidad central para el desarrollo de la humanidad?

- ¿Cómo la autonomía induce a un compromiso amoroso para desarrollar capacidades internas de emociones y toma de decisiones en los integrantes de la familia?

- ¿Cómo las capacidades secundarias ayudan al desarrollo de la autonomía para potenciar capacidades internas como la educación, el emprendimiento y otros?

- ¿Cómo la cultura es un determinante que limita o promueve emociones para el cultivo de la humanidad?

Las respuestas a las preguntas posibilitaron plantear los siguientes objetivos:

- Analizar cómo la autonomía posibilita crear capacidades y emociones en la familia, y cómo puede proyectarse como un ideal de gobierno que implique al Estado, las instituciones y la sociedad, para generar transformaciones que cultiven la humanidad en una sociedad caótica que evoluciona en el ámbito cultural.

- Establecer el papel de la autonomía de la familia ante los desafíos de la sociedad contemporánea, en el ámbito ético, social, político y cultural.

- Determinar cómo la autonomía crea capacidades en la familia a partir del amor, de la entrega generosa y servicial en torno a un ideal de humanidad, que gravita en la satisfacción de necesidades primarias y secundarias de la sociedad y que parte del bien común, los valores y la justicia.

- Identificar la autonomía como generadora de capacidades internas, que ayuden a aprender a pensar por sí mismo en torno a proyectos familiares que conlleven la toma de decisiones con 
base en compromisos amorosos, afiliación y participación en el cultivo de la humanidad.

- Esbozar la manera como la familia accede a las capacidades secundarias para impulsar las capacidades internas, a partir de la política, la educación, el emprendimiento, los espacios recreativos, el internet y otros contextos.

- Analizar el impacto de la cultura en el desarrollo de la autonomía para crear capacidades en la familia y cultivar la humanidad.

Los objetivos expuestos anteriormente direccionaron el desarrollo de la investigación, para analizar la autonomía como creadora de capacidades y emociones en la familia desde la perspectiva de la humanidad y la cultura.

\section{Marco de referencia conceptual}

\section{La concepción de autonomía en la familia}

La familia vive el gran reto de la autonomía, pues gran parte de su vida gira sobre la heteronomía del mundo secularizado, donde se imponen estilos de vida que se apartan del amor, que es la clave para combatir momentos de presión propiciados por el mercado, la tentación de la droga, el consumo, la pobreza y la miseria, catalizadores de una aculturación proveniente del mundo foráneo. Esta aculturación, como se dijo, conlleva la apropiación de prácticas que atentan contra el núcleo familiar, especialmente contra aquellos que viven en la periferia, sin descartar los de la clase media y alta que tienen otro tipo de problemas, pero todos atravesados por dilemas éticos y morales. Entonces, la clave radica en una vida buena de la familia, que se impregne del amor para la toma de decisiones y la búsqueda de bienes materiales, y así poder subsistir en un mundo cambiante y caótico. La vida buena se concibe por el amor que se infunde a cada integrante de la familia para vivir experiencias agradables y desagradables, tomar la iniciativa, sin perder de vista la ética y la moral. En otras palabras, el amor 
infunde la capacidad de apropiarse de las virtudes, tal como lo sostiene Aebli (1998), quien ve en las convicciones morales una conciencia clara acerca de los derechos de las otras personas, la mesura o autocontrol para actuar en la vida, la justicia, la sabiduría para discriminar las acciones del comportamiento humano en sociedad, en especial, ve en ello la capacidad de gobernarse con amor y brindarlo a los demás, para asumir acciones cognitivas y evaluativas que redunden en cultivar la humanidad: "Vemos ahora, que se trata de la forma clásica del amor al prójimo. Su forma clásica se halla en la parábola del buen samaritano" (p. 92).

La contemplación, la observancia y la vivencia de las virtudes teologales es determinante en el desarrollo de la autonomía de la familia, porque son los pilares para comprender la entrega amorosa y generosa al otro, que vive tiempos azarosos y peligrosos en una sociedad líquida que moldea las relaciones familiares e interpersonales, la sexualidad, el amor, la ética relativa, los estilos de vida que promueven los medios de comunicación para dar rienda suelta a los placeres, la trata de personas, la prostitución, el feminicidio, el maltrato a los niños. En fin, hay tantos moldes que se vuelven a reconfigurar y a recomponer, que se convierte a la familia en parte de esa sociedad. De ahí que haya que convertir a la familia en un buen samaritano que ame con toda la humanidad para cultivar más humanidad, que ayude a luchar contra toda forma de opresión que intente someter la dignidad de la persona a circunstancias que nieguen el florecimiento de la vocación amorosa, la voluntad de servir al prójimo y amar de forma generosa a los integrantes de la familia. Esto con el fin de tomar la iniciativa que posibilite un gobierno del amor, en medio de realidades líquidas. Por ende, la autonomía, según Gonzales y Marquínez, se entiende como "darse a sí mismo sus propias leyes, no significa hacer lo que a uno se le da la gana, sino hacer lo que uno cree que debe hacer, porque es lo más conveniente para sí y para los demás” (1999, p. 60).

La autonomía se sustenta en el valor de la firmeza, cuando cada uno de los integrantes de la familia procede de manera justa, respetando la dignidad y los derechos humanos. Esto quiere decir que la puerta de entrada a la autonomía es la dignidad de la persona. Por tal razón, 
Para algunos, "dignidad" proviene del término latino dignitas, cualidad sobresaliente o excelencia; dice relación o merecimiento de un "honor". Para otros, "dignidad" tiene origen en el término griego $\alpha^{\prime} \xi \hat{i} \omega \mu \alpha$ (axioma), tomando entonces, una significación como merecimiento de un "valor". Así, pues, por "dignidad" se entiende algo merecido por alguien como "valor" u "honor". Por esto, en el lenguaje corriente se dice que alguien es digno para indicar que posee ciertas virtudes como la bondad, la lealtad, la honestidad, la rectitud, y que por ello merece honra. (Sastoque, 2001, p. 196)

En otras palabras, la familia tiene que encarnar las virtudes del amor, compasión, caridad, misericordia, bondad, generosidad, tolerancia, humanidad, servicio, entrega, reciprocidad, paciencia, escucha, perdón. Este reto es un entramado complejo para vivirlo como principio, sobre todo cuando las virtudes no se practican para honrar a los integrantes de la familia y la sociedad. Estas virtudes están bombardeadas por una sociedad que juega a destruir el honor, por fuerzas del mundo secularizado, capitalista, técnico y tecnológico, por los medios de comunicación y el mundo digital, por citar solo algunos, debido a que la marginalidad, la pobreza, el hambre, la miseria, la ambición, la riqueza, el poder, alimentan falsos honores y destruyen la dignidad de la persona. Esto significa que la autonomía, basada en el valor de la firmeza, requiere del concurso de la sociedad, el Estado y las instituciones, para que brinden posibilidades de crecimiento que salvaguarden el honor, atendiendo las necesidades básicas y secundarias de la familia. Por esta razón, se necesita una sociedad que asimile el planteamiento kantiano, el cual refiere "que los principios buenos constituyen un 'reino de los fines', una sociedad virtual de seres libres que se respetan mutuamente como iguales" (Nussbaum, 2008, p. 66). El ser bueno ya es un síntoma de máximo valor de la dignidad humana, lo que supone un buen ejercicio de la libertad.

La mesura o el autocontrol en la autonomía de la familia es una virtud valiosa que no debe ceder a las fuerzas del mal que atenten contra la libertad y la dignidad de la persona. Esto conlleva la autorregulación cognitiva, emocional y moral, a concebir que el amor es una experiencia práctica de liberación que comprende los errores y los ensayos, los 
aciertos y desaciertos, el mal y la atrocidad del obrar humano, para dirigirlos hacia el bien común. Se necesita sentir con el corazón y actuar con la mente para superar situaciones de negación de la humanidad (que arrastra con los males del mundo secularizado) para crear un microcosmos capaz de luchar con un caparazón de virtudes y de discernir entre lo bueno y lo malo. Se trata de gobernar con un sentido emancipatorio las pasiones, los deseos, los impulsos, los placeres, la violencia y la muerte, para convertirse en mejores personas, que educan en el justo medio de la ética con el fin de evitar los excesos en torno a la libertad.

Por otra parte, la justicia es clave en el desarrollo de la autonomía de la familia, ya que se necesita de personas honestas, transparentes y rectas, lo cual se percibe a través de la conducta y el comportamiento propio en interacción con los demás. Esta virtud es indispensable en una ética del cuidado de la familia. Sin embargo, se presenta una relatividad cuando el valor fundamental de la justicia no es una forma de vida, sino que se impone el escenario que pregona el mundo secularizado y los medios de comunicación, con valores como la deshonestidad, la corrupción, la mentira, la falsedad, la ausencia de amor, la codicia, el poder, el éxito, la competencia. Esta forma de vida contamina la familia, no concibe la justicia como la regla de oro que transforma el mundo, omite que la práctica de la justicia inicia en el hogar. Esta premisa hoy en día está subvalorada, al reemplazar lo que es justo por la avaricia personal, y relegar a un segundo plano la humanidad del otro. De esta manera, la autonomía significa tomar siempre la iniciativa de la justicia, con el fin de obrar con sentido del bien común; beneficiar no solo a un individuo, sino a todo el colectivo o grupo.

La autonomía de la familia también se centra en el amor al prójimo, ya que es un ingrediente esencial para mantener la solidaridad y la reciprocidad de forma generosa y bondadosa. Los problemas de convivencia, injusticia, inequidad, la disfunción en las relaciones humanas, agresiones y violencia, el machismo, el feminicidio, la vida paupérrima y marginal, el hambre y la miseria, y otras circunstancias sociales, han minado lentamente los valores que encarnan el amor propio y el amor al prójimo. Por consiguiente, sostiene Aebli (1998) que la parábola del 
buen samaritano y las reflexiones de la filosofía han gravitado en torno al amor, lo que indica que la naturaleza humana siempre persigue el amor y la felicidad, porque desea conocerlos. Es urgente colocar en el centro de la vida de la familia el amor al prójimo, es urgente ponderar el amor en medio de los errores, de las malas decisiones, de juicios y acciones violentas, de desconocimiento y falta de respeto, de pérdidas de seres queridos por cuestiones de la violencia, de ausencia de disciplina, de la pérdida del amor fraternal, de la falta de compromiso con el otro en lo emocional, cognitivo y evaluativo, del abandono de los niños por múltiples motivos. Estos y otros problemas más, cuando no se ama y no hay compromiso con el prójimo, son el peor síntoma de degradación ética y moral. Es importante entender que cuando se ama, se reconoce y se asume un compromiso con la dignidad del otro, con todas sus imperfecciones y virtudes; siempre está presente el amor incondicional que se brinda al otro tal como es.

Pero hay otra cosa, para Aebli (1998) la sabiduría se manifiesta en tres virtudes: "firmeza, mesura y justicia. Otros le añaden una connotación autónoma, con la cual lo entienden como comprensión” (p. 90). En otros términos, la sabiduría como comprensión implica una inteligencia intuitiva, relacional, racional y emocional, que es capaz de ver el todo y las partes, para actuar con un dominio de sí mismo, con cordura y justicia. La autonomía en la familia, desde la perspectiva de la sabiduría, se hace notoria, en parte, cuando las creencias determinan lo que es cada miembro de la familia, cuando esta comprende la serie de fenómenos que configuran la sociedad líquida y la pérdida de humanismo, cuando razona para pensar la vida y el respeto por la dignidad de la persona, y cuando comprende la inteligencia emocional, que hace referencia a la simpatía, la empatía y la afinidad.

\section{Concepción sobre crear capacidades y emociones}

Nussbaum acuña la expresión crear capacidades, con el que se aparta del enfoque de competencias que resulta del lenguaje promovido por la ideología neoliberal y la globalización en el mundo empresarial, y que posteriormente toca las puertas de la educación contemporánea. Así, la filósofa estadounidense propone otras categorías para estudiar 
el desarrollo humano, que se apartan de los postulados del Banco Mundial. Los términos crear capacidades y desarrollo bumano parten de la pregunta “¿Qué son capaces de hacer y de ser las personas? Por decirlo de otro modo, son lo que Sen llama 'libertades sustanciales', un conjunto de oportunidades (habitualmente interrelacionadas) para elegir y actuar" (Nussbaum, 2012, p. 40). Dichos términos se refieren a las libertades y las combinaciones alternativas para saber elegir y tomar decisiones de índole personal. Del mismo modo, se habla de las capacidades emocionales e intelectuales para trabajar capacidades combinadas (saber actuar en el mundo social, político y económico). Ahora, las capacidades internas se conciben como la dotación o equipamiento innato de cada persona para actuar en la vida. Por otro lado, las capacidades básicas se refieren al trato de las personas en términos de igualdad y de acuerdo con la dignidad; actuar con un sentido evaluativo de justicia acerca de la naturaleza humana. Nussbaum (2012) también habla de diez capacidades centrales que forman parte del ámbito político, entre ellas está la vida, salud física, integridad física (sentidos, imaginación y pensamiento), emociones, razón práctica, afiliación, juego y control sobre el propio entorno. Puede decirse entonces que crear capacidades implica pensar en alternativas que materialicen la justicia social desde la perspectiva de la dignidad de la persona, tanto en un orden individual como colectivo.

Ahora, la autonomía para crear capacidades y emociones en la familia parte del amor como una capacidad de servicio y entrega al otro, entendiendo que es la máxima capacidad transversal para crear otras capacidades, para aprender a actuar con un sentido de protección, solidaridad, generosidad, misericordia, compasión, caridad, perdón, tolerancia y cuidado. Esto significa que la máxima expresión de la capacidad de la familia es el amor, porque la orientación y la corrección con el corazón hacen que surjan las mejores emociones cognitivas y evaluativas de los individuos y del colectivo, pues logran sacar lo mejor en circunstancias críticas que niegan la humanidad, y crea nuevas capacidades de reconocimiento y de compromiso hacia la dignidad de los demás y el establecimiento de la justicia social. El amor cambia al individuo cuando el afecto y el sentimiento siembran la semilla de una experiencia emocional, de una conciencia amorosa cognitiva que 
compensa, con valores encarnados y habilidades éticas y morales, la contaminación del mundo líquido de una forma creativa e imaginativa. Esto indica que la primera instancia en la que se debe educar en el gobierno de los valores es la familia, lo que significa vivir y experimentar el amor en todo el sentido de la palabra, ya sea en la riqueza o la pobreza, en la prosperidad o con la alacena vacía, la vida o la muerte, el trabajo o el desempleo, la nutrición o el hambre, la educación o la ignorancia, el emprendimiento o la drogadicción; o sea, en todo lo que concierne a la vida y a los organismos vivos. Las emociones en la niñez "se desarrollan gradualmente, a medida que el pequeño se va haciendo más y más consciente de la importancia que tales transformaciones revisten para su vida, así como el hecho de que, por decirlo de algún modo, llegan desde fuera" (Nussbaum, 2008, p. 223).

De ahí se desprenden las capacidades centrales que están enfocadas en la autonomía del individuo, desde donde se cultiva la humanidad. En otras palabras, la familia es la primera instancia cuando se trata de formar en los valores de justicia, equidad, igualdad, amor, solidaridad y diálogo. Sin embargo, es a partir de la libertad que el hombre aprende a elegir la búsqueda del bien común en una sociedad mercantilista, xenofóbica, racista, de la que se derivan fenómenos tales como la trata de blancas, el abuso sexual, el maltrato a la mujer, o sea, todas aquellas acciones que atentan contra la dignidad de la persona. Ante estas circunstancias negativas, la autonomía, vista como la posibilidad de elección de valores, está bombardeada por una heteronomía de la relatividad, en la que todo vale de acuerdo con las emociones y razonamientos de las subjetividades en la política, economía, arte, estética, cultura, técnica y mitología, tendencias de la nueva era, posiciones religiosas y teológicas, generando una total dependencia de sistemas que minan la integridad de la familia, con consecuencias graves para la sociedad contemporánea. Por ejemplo, jóvenes europeos que se unen a la militancia yihadista para fomentar la violencia y la muerte e inmolar los cuerpos en la búsqueda del paraíso, o jóvenes colombianos que se vinculan a grupos beligerantes para sembrar la muerte y la violencia. Por tal razón, "la autonomía de la persona no debe confundirse con un subjetivismo individualista y excluyente [...] No es la individualidad la que confiere la autonomía, sino la personeidad" (González y 
Marquínez, 1999, p. 59). Esto es así, en cuanto que el hombre es sujeto de reflexión y de razonamiento para gobernar y proponer leyes que beneficien al individuo y al colectivo.

También la autonomía debe posibilitar la creación de capacidades secundarias en la familia, para que los integrantes se articulen de forma activa y democrática a las experiencias de la vida política, social, cultural, económica y científica. Esto implica que la familia tiene que crecer en capacidades que la proyecten para participar de la vida y realizarse plenamente en la sociedad, con el grado de bienestar y comodidad que proporciona el mundo de la recreación, la educación, el emprendimiento y la productividad, la tecnología y la ciencia, el humanismo y la sensibilidad por el otro. Esto requiere de la participación del Estado, las instituciones, la empresa, la sociedad civil, y de la formulación de una política de sostenibilidad que piense en el individuo y en el conglomerado. En América Latina esto resulta muy complicado, pues reinan circunstancias negativas que anulan la humanidad de la mayoría de la población, aquella que vive en los márgenes de la sociedad, desarraigada del progreso y de la buena vida. Por tal motivo, urgen cambios que consideren la familia como el motor del desarrollo humano, pero requieren inversión de recursos económicos, ideas y proyectos que materialicen el cultivo de la tecnología, la ciencia y el humanismo; esto significaría crear una contracultura en el imaginario de la familia, la sociedad y el orden global.

Igualmente, la familia tiene que cultivar capacidades en torno a cualidades como la convivencia, la escucha, el diálogo, la tolerancia, la justicia, la equidad, la libertad, la sensibilidad hacia el otro y el respeto a la dignidad de la persona; en otros términos, aprender a ejercer un rol proactivo de transformación del entorno mediante una participación en lo social, cultural, político y económico, pero desplegando acciones y actos concretos que persigan la solidaridad y el bien común, para luchar frente al mal con base en una reflexión crítica de las situaciones. Por tal motivo, la familia tiene como tarea urgente la reencarnación de los valores, para mostrar una postura moral tan sólida como una roca, en lo individual y colectivo, para hacer esto evidente en acciones tangibles que recurran a la verdad y a la toma de conciencia deliberada, y así luchar contra una sociedad caótica, desordenada, 
etérea, desigual, deformada, que sigue en el camino de la depredación y amplía el terreno de la erosión. Por consiguiente, "podemos ser amables el uno con el otro o pelear; coexistir en paz o tendernos trampas [...] mantenerlos intactos requiere concreto sólido y guardias que vigilen" (Bauman, 2015, p. 83). El protagonismo de la familia gravita alrededor de la ética, para realizar intervenciones honestas y sinceras que impacten más en el propósito de abrazar el bien.

El concepto de la autonomía para crear capacidades y emociones dentro de la familia, en tiempos de caos, tiene como referente la teoría de Nussbaum (2012). Sin embargo, al mismo tiempo se aparta de estos postulados para reinventar el concepto según el contexto que vive la familia en la sociedad colombiana. Este viraje se centra en el amor, como una de las grandes capacidades para promover otras capacidades. Esto quiere decir que el enfoque de las capacidades sufre mutaciones en cuanto al concepto focal, la realidad social y la reflexión filosófica, haciendo primar la naturaleza del problema; en este caso, esa naturaleza radica en el amor, porque es la conciencia amorosa la que posibilita la deliberación y la toma de decisiones, para que cada miembro cuide del otro, para que la familia se nutra de la perfección de las virtudes y de las imperfecciones humanas, pero siempre, con la alerta y la delicadeza de hacer el bien, de promover la dignidad de la persona; es una pretensión de vida que deja huella en el cerebro de los padres y que ha permitido que el hombre pueda sobrevivir en circunstancias tan complejas y de sobresaltos. El propósito de hacerse humano está "centrado en la biología del amor como el dominio de las acciones que constituyen al otro como legítimo" (Maturana, 2007, p. 44).

\section{La familia desde la perspectiva cultural}

La cultura es un determinante o un detonador de cambios en las prácticas cotidianas de la familia, es un marco que establece estilos de vida. La cultura se nutre de tradiciones discursivas, de simbologías que se transmiten de generación en generación, de hechos y circunstancias históricas que mantienen estructuras, hábitos, costumbres y creencias que se cumplen por tradición, incluso de formas aculturales, foráneas, que ganan terreno para instalarse en las mentes y vidas de los 
integrantes de la familia a través de los medios de comunicación (que presentan modas atractivas) o a través de la fuerza de las tecnologías, o por la irrupción de esquemas de vida hedonistas, mercantilistas, consumistas, políticos, religiosos, económicos, etc. Considerando que los "hechos culturales podían interpretarse a la luz de un fondo de hechos culturales sin disolverlos en ese fondo ni disolver el fondo en los hechos mismos" (Geertz, 2006, p. 46), puede decirse que las aristas de la política, la economía, la psique, la religión, el arte, la ciencia, la tecnología y los medios de comunicación se encargan de ejercer diversos grados de presión en la familia, que no es capaz de disolver semejante cúmulo de componentes y pierde la conciencia en el cultivo de la humanidad.

La familia se determina por el espacio social, constituyéndose en un componente cultural que establece linderos imaginarios y reales: quienes son familias paupérrimas o marginadas se encuentran en la periferia de la ciudad; las de clase media se ubican en espacios emergentes para acceder al trabajo, la educación, el emprendimiento y la empresa, en lugares con cierta homogeneidad de edificios que colindan con barrios populares, y las familias de clase alta, en espacios locativos boyantes por la arquitectura y el lujo. El espacio social indica el sistema de posiciones de las familias, la jerarquización de las clases baja, media y alta. Allí se presenta una caracterización del tipo de familia que habita en la ciudad. Este espacio social es un referente de los hábitos, de las costumbres y comportamientos de las familias, en cuanto a vivienda, trabajo, estudio, interacciones humanas psicológicas y éticas, que marcan la forma como se educa a la prole. Por ende, el espacio social para algunas familias carece de bienes primarios y de recursos materiales; en cambio, las que ascienden por la vía de la educación y el trabajo tienen los bienes necesarios que brindan felicidad; y las que están en la cúspide social, cuentan con las comodidades y las capacidades económicas para intervenir en la vida, la política, la cultura, la educación y con lo necesario para sobrevivir, en un espacio de confort y comodidad.

El espacio social es el escenario que posibilita el juego de roles y de ascensos ante las vacantes que dejan otros individuos en la compleja red de búsqueda de metas individuales y colectivas. La familia experimenta este juego de los campos sociales, específicamente en América 
Latina, donde los cambios se gestan por motivos externos como la violencia, la drogadicción, la moda, el impacto de la ciencia y la tecnología, por nombrar algunos. Sin embargo, cuando las circunstancias se mueven en el marco de la eticidad, para los integrantes de la familia es una muy buena oportunidad de cambio de roles y de estatus, que favorece la promoción y el mejoramiento de la calidad de vida. Pero, si se mantienen hábitos que atentan contra la dignidad de la persona, lo más seguro es que se agudice la crisis del espacio social, y permanezca un cambio aparente, que responde a expectativas inmediatistas y devora proyectos de vida. Igualmente, las familias de un nivel de vida alto, perciben las acciones de los espacios sociales de cada integrante de la familia de una forma muy confortable porque, en parte, la vida está asegurada por la economía, por un proyecto educativo, de emprendimiento y de producción, que asegura los logros y el ascenso social.

Los hábitos de las familias dependen de la realidad y los ideales propuestos en la vida, así como de la capacidad de convivencia, tolerancia, justicia, amor, entrega, compromiso, reciprocidad; de las experiencias positivas de aceptación y reconciliación. Sin embargo, las circunstancias externas que provienen a través de los medios de comunicación han alterado los hábitos: el afán de riqueza, la moda, el divorcio, los diferentes tipos de familia, las prácticas sexuales, la trata de personas, la violencia y el secuestro; es decir, existen una multiplicidad de circunstancias que siembran bondad o maldad, y que alteran el comportamiento, la conducta, las creencias, los valores y actitudes de la familia. Los hábitos se convierten en las biografías de los individuos y colectividades, que se reconfiguran con emociones y racionalidades propias de estos, y que están combinadas con aspectos foráneos. Es una fusión de aspiraciones y anhelos que se pueden convertir en un volcán de deseos y realizaciones personales, siempre que se den las condiciones apropiadas en el momento adecuado. También se constituyen en bombas de tiempo que destruyen y acaban vidas, cuando los hábitos son malsanos y se alimentan de pobreza, miseria, analfabetismo, desempleo, hambre, falta de justicia, carencia de servicios básicos, deudas y demás; aspiraciones que se encargan de distorsionar las biografías, cuando no logran realizarse, o cuando no se adaptan a los modelos de familia diseñados por la sociedad de oferta y consumo. 
Por otra parte, la simbología en la cultura depende de la percepción que tenga el ciudadano del hábitat, de las capacidades educativas, laborales y de emprendimiento y de los anhelos de bienestar y felicidad, por nombrar algunos aspectos del mundo. O sea que la simbología se acompaña de una semántica que nutre un estilo de vida, según las circunstancias que viva el individuo, ya sea en un entorno rico de posibilidades de progreso personal o de negación de la humanidad. Esto quiere decir que la biografía de los integrantes de la familia se alimenta de la cultura, esta influye a través de los signos y símbolos en los deseos y aspiraciones, las frustraciones y desesperanzas, en la conformidad y estabilidad. La cultura es entonces un limitante o un catalizador para impulsar a la familia en la autonomía o heteronomía, respecto a los proyectos que promueva la sociedad, que para algunos son grandes murallas para realizar el proyecto de vida personal, en cambio, para otros, una excelente oportunidad, según el contexto económico, social, cultural, productivo y científico. Es decir, el capital simbólico en los ámbitos de la vida del hombre se circunscribe a la realización o no de los anhelos personales de la familia, que están determinados, de cierto modo o de forma contundente, por los medios de comunicación, la economía, el mercado global, la aculturación de estilos de vida, la apuesta de un mundo secularizado, y la vida de confort que brinda la ciencia y la tecnología.

Los actos simbólicos de intercambio en las sociedades latinoamericanas presentan una asimetría, en cuanto existen unas familias que tienen el poder económico, social, cultural y científico, y otras que buscan los medios y los recursos de ascenso para equipararse con aquellas que tienen bienestar y confort, aquellas que buscan en la educación un recurso potencial para posicionarse a corto y mediano plazo, con un sacrificio inmenso, austeridad e inteligencia disciplinada. Los actos simbólicos de reconocimiento no forman parte de una vida de calidad para las familias que viven en la marginalidad, en una vida paupérrima, porque la pobreza, la miseria y el analfabetismo son componentes de negación de la humanidad que distorsionan la buena vida y la felicidad. En consecuencia, aparecen alternativas como el narcotráfico, la drogadicción, el vandalismo, el secuestro, la prostitución, por enumerar algunas de las vías que brindan reconocimientos económicos mediante acciones 
que carecen de eticidad y moralidad, que proporcionan una felicidad ingenua fundada en la apropiación de bienes materiales que proyecten seguridad, en la apariencia de una vida buena que se percibe en la conducta doble de un grupo significativo de individuos que pierden la conciencia sobre el bien común. Por ello, “el ejemplo más interesante de esta especie de alquimia simbólica sería la transfiguración de las relaciones de dominación y explotación" (Bourdieu, 2007, p. 169). La anterior posición confirma que el intercambio de obsequios entre ricos y pobres es de desigualdad, lo cual incide en el desarrollo de la autonomía, en todo lo que compete a una buena calidad de vida de los integrantes de la familia.

\section{Discusión y debate: la autonomía como la capacidad para crear capacidades y emociones}

La autonomía (en la familia) atraviesa la pérdida de su columna vertebral, que es la valoración de lo que haga el individuo por iniciativa propia, los proyectos personales y familiares que revindiquen todos aquellos valores basados en la dignidad humana, es decir que en la familia se viva la capacidad del amor como entrega generosa y servicial,: cuidar de la prole, de los enfermos y discapacitados, compartir el alimento para que todos se nutran por igual, poner el goce personal al servicio de la felicidad de la familia, ser capaz de sacrificarse y luchar por los ideales de vida de cada uno de los miembros, aprender a trabajar para facilitar los recursos mínimos a la familia, enseñar a los integrantes la ruta de la educación, para que aprendan a pensar y participar en la construcción de la democracia, vivir la moralidad y la ética para actuar con transparencia, contar con un techo, alimento y medios de supervivencia, aprender a argumentar y contraargumentar para llegar a consensos que posibiliten la movilidad y la participación en la complejidad de los discursos, aprender las nuevas costumbres y la urbanidad, promover la hospitalidad como medio para ejercer el papel de un buen samaritano, dialogar para superar los problemas de la cotidianidad, recrear la familia en escenarios que superen la modernidad 
líquida. Por tanto, acá toma relevancia lo que entiende Nussbaum (2012) por crear capacidades:

¿Qué es capaz de hacer y de ser cada persona? Dicho de otro modo, el enfoque concibe cada persona como un fin en sí mismo y no se pregunta solamente por el bienestar total o medio, sino también por las oportunidades disponibles para cada ser humano. (p. 38)

Además de concebir el amor como la capacidad central, la familia también necesita contar con una vivienda, con salud, fuente de empleo, educación, contar con un buen ambiente, buenas relaciones interpersonales, potenciar el desarrollo de la inteligencia, aprovechar los recursos de la naturaleza para formar parte de la experiencia en la tierra y tener un dominio del entorno. No obstante, en países con un bajo nivel de calidad de vida, con un alto índice de afectaciones al desarrollo humano de la familia (que se refleja en las costumbres, actitudes, conductas y creencias), se altera todo el panorama. ¿Cómo vivir y sentir la autonomía en situaciones negativas que mutilan el cultivo de la humanidad? Se requiere disponer de capacidades protagónicas, de una intervención y participación política del núcleo familiar, de escenarios que favorezcan el emprendimiento por parte del Estado, de entidades privadas, y de una sociedad que genere oportunidades de igualdad y equidad. Lo anterior indica que la autonomía con la que se logra el desarrollo humano de la familia, está emparentada con la autonomía que promueven y promulgan las instituciones en lo educativo, jurídico, político, económico, cultural, productivo, artístico y social. O sea que la autonomía apunta a sectores externos a la familia para alcanzar un ciclo armónico que la realimente, con el fin de que la autonomía no esté limitada por circunstancias y recursos que nieguen el desarrollo humano y no posibiliten la eclosión de esa nueva larva que tiene como horizonte cultivar la humanidad. De ahí que "las capacidades pertenecen, en primer y prioritario lugar, a las personas individuales, y solo luego, en sentido derivado a los colectivos" (Nussbaum, 2012, p. 55). Esta premisa, en el contexto latinoamericano, no es fácil de percibir cuando el desarrollo autónomo 
interno de la familia depende de circunstancias ajenas, cuando no se potencia la iniciativa y el gobierno de padres e hijos en función de metas concretas que respalden la dignidad de la persona.

El crear capacidades en términos de autonomía significa que la familia debe saber lo que todos los miembros son capaces de hacer para mejorar las relaciones humanas, los roles que corresponden a los padres y a los hijos, las tareas y los proyectos que pueden asumir conjuntamente; significa que la familia debe arriesgarse más por los débiles, proteger a todos los integrantes de la contaminación y de la vaciedad del mundo, valorar la intervención de cada miembro y, sobre todo, saber que la fidelidad es un compromiso de entrega total basado en el amor. La autonomía como generadora de capacidades centrales se convierte en un imán para mantener aglutinada e integrada la familia en el amor, esto implica que los intereses de la familia se afinquen en el bien común, dejando a un lado el egoísmo, la envidia, la exclusión, la competencia, el poder, el autoritarismo, los celos y todo aquello que pueda dar cabida a la maldad. También, la autonomía de la familia radica en la formación humanística de la persona para gobernarse a sí mismo en el uso apropiado de la libertad, para que no afecte a ninguno de los integrantes, ni a la sociedad. Esto tiene que ir acompañado con los medios y los recursos económicos para garantizar un futuro de oportunidades laborales, algo muy complicado para la sociedad de América Latina, donde existe una población marginada. En este contexto la familia tiene que cultivar la autonomía para superar las adversidades que obstaculizan la formación humana y el logro de las metas personales y colectivas, haciendo de la imaginación el medio ideal para que cada integrante piense por sí mismo y sepa qué hacer en circunstancias que niegan al otro. Por tanto, “cuanto más evoluciona una sociedad, cuanto más compleja y rica en ofertas se hace, más apoyo presta al yo de cada uno de los miembros" (Savater, 2008, p. 30).

La autonomía implica que la familia asuma los valores para inventarlos y reinventarlos, con el interés de educarse en torno a la solidaridad, la reciprocidad, el apoyo mutuo, la colaboración, el trabajo en equipo, y con el propósito de hacer el bien y únicamente el bien. La realidad de la sociedad actual se impone con medios e ideas que 
van en contravía de una ética y una moral del compromiso compartido, porque los medios de comunicación aluden al más fuerte, tramposo, avispado, perezoso, a la relatividad en la internalización de los valores, en la forma como piensa y actúa cada individuo. Además, los problemas económicos, sociales y políticos arrasan con el germen de una autonomía intelectual, moral y científica que está a punto de eclosionar en el seno de la familia. También se ha perdido el sentido de la fidelidad en los compromisos sentimentales y de pareja, dejando la prole a su suerte, lo que rápidamente contamina el mundo y lo conduce a actuar como lo hace la sociedad líquida. Esto significa que el Estado, la sociedad civil y la escuela deben asumir la formación de la familia - con campañas y acciones concretas acerca del papel de la ética y la moral, la autonomía, en torno al respeto por la dignidad de la persona y la necesidad de hacer el bien, de actuar correctamenteempleando todos los dispositivos disponibles de índole cultural, político, económico, social, comunicativos y tecnológicos que contribuyan a mejorar su calidad de vida.

Las situaciones de injusticia, desigualdad social e inequidad tienen las raíces en la formación humana de las familias, de las grandes castas económicas que forman un pensamiento de imperio en las futuras generaciones, que los relevarán en el poder. La falta de sensibilidad hacia los marginados, la toma de decisiones emocionales y cognitivas basadas en la rentabilidad del capital y la explotación del más débil, la ausencia de transparencia y de sostenibilidad de una política de justicia en términos de igualdad para los pobres y ricos, todo esto hace pensar qué tipo de formación humana se imparte en la familia de los acaudalados, empresarios, políticos, clase media, clase trabajadora, clase estrato alto, pobres, marginados, guerrilleros, relegados y desplazados por la violencia. Esto quiere decir que la autonomía tendría diversas modalidades y enfoques para lograr un solo propósito, como es la justicia y la igualdad, cambiando en unos la mentalidad de la heteronomía por la autogestión de la autonomía, y en otros logrando que la autonomía se desborde con un sentido de humanidad y de compromiso con el otro.

Entonces la autonomía, como la capacidad para crear otras capacidades internas en la familia, es el cimiento de varios pilares: pensar 
por sí mismo y por los integrantes del núcleo familiar (con el fin de tomar decisiones y acciones amorosas compromisorias, apoyadas en el bienestar y la calidad de vida), rehacer y recrear los lazos sentimentales para que los integrantes asuman un compromiso con la realidad, cuidar y proteger a los jóvenes y a los ancianos, sentir compasión y responsabilidad frente a los enfermos y discapacitados, participar en el proyecto de crecimiento de la prole para que le sirva a la sociedad, vivir los valores para dignificar a la persona, formar y apropiarse de una mentalidad de emprendimiento para sobrevivir y ayudar a otros, repensar y reinventar la forma de gobierno para asumir los retos de la sociedad actual a través de la educación, la inteligencia, las emociones, el emprendimiento, la productividad y la gestión en el ámbito político. Esto quiere decir que

Una de las tareas que corresponde a una sociedad que quiera promover las capacidades humanas más importantes es la de apoyar el desarrollo de las capacidades internas, ya sea a través de la educación, de los recursos necesarios para potenciar la salud física y emocional, del apoyo y atención y el cariño de los familiares, de la implantación de un sistema educativo, o de otras muchas medidas. (Nussbaum, 2012, p. 41)

Por otro lado, la autonomía crea capacidades de afiliación y participación en la familia cuando los miembros descubren la necesidad de que afloren la creatividad y el ingenio, la necesidad de trabajar en equipo y aprender a compartir las utilidades, para que todos realicen el proyecto de vida personal. Sin embargo, el Estado, las instituciones educativas, las empresas y la sociedad civil tienen que promover espacios de afiliación y participación para la familia, propiciar que sus integrantes cuenten con los recursos económicos necesarios para proyectarse en el trabajo, en el estudio y en otros ámbitos, todo con el interés de mejorar la calidad de vida. En países de América Latina, acceder a las capacidades de afiliación y participación en el trabajo genera frustración, tristeza y depresión; se niega el desarrollo humano, necesario para crecer en igualdad y equidad. Por tanto, la familia tiene que buscar 
todos los medios de forma inventiva y pensar cómo se provee un trabajo basado en la cooperación de sus integrantes, para vérselas con la vida. Esta premisa de unir esfuerzos para vencer las penurias de la vida puede convertirse en un proyecto de emprendimiento que adquiere un nicho de negocio, en el cual todos salen beneficiados en el sentido de que el trabajo dignifica a la persona, pues esta se siente importante al convertirse en un buen proveedor para la familia, de la cual se desprenden otras grandes oportunidades para la realización personal.

Es primordial cultivar en la familia la autonomía para que esta descubra en la creatividad la gran herramienta para resolver problemas en el ámbito de la cultura, la economía, el arte, la religión, la sana convivencia, el emprendimiento y la productividad. Esto quiere decir que la autonomía dispara otras capacidades, en las que el ingenio tendrá una diversidad de formas para que asuma el pensar, como un gran valor de autoestima, decisión, riesgo, salir de la comodidad, actuar, amar, querer, sentir reciprocidad, vivir la alteridad, compasión, misericordia, justicia y equidad. La autonomía percibida de esta manera tiene que gatillar una inventiva explosiva que no puede detenerse, para crear procesos de reingeniería que transformen la familia en un gran tanque de gestación de capacidades centrales, internas, de afiliación y participación, secundarias y protagónicas. Esto significa que la autonomía, en la perspectiva del desarrollo humano en la familia, sorteará una serie de problemas en que la reciprocidad y el diálogo, regentados por una inteligencia emocional y racional activa y propositiva, le apostarán por la dignidad de la persona para que persiga siempre el bien común de todos los integrantes.

Ahora, es importante que la familia acceda de forma autónoma a las capacidades secundarias mediante la educación, las cuales se constituyen en un puente determinante para impulsar las capacidades internas. También es verdad que las dificultades para acceder a la educación superior para la familia con escasos recursos económicos y la clase media es un gran problema para realizar el proyecto de vida personal. La educación superior es un factor determinante para crear confianza y seguridad en torno a motivos y acciones duraderas que posicionen un futuro de bienestar. Es decir que la capacidad secundaria en la educación se convierte en la extensión de otros proyectos 
internos de la familia para lograr una realización plena en términos de una sociedad más justa y equitativa. Esto hace pensar que los países de Latinoamérica tendrán que crear espacios políticos y productivos con fundamento en la autonomía, para que todos puedan acceder a la educación; pues son las mentes más preparadas las que forjan una autonomía de seguridad laboral, de apoyo económico familiar, de mejor calidad de vida, para participar con un nivel cognitivo en la solución de problemas que afectan a la sociedad, y alcanzar una independencia individual que genere un buen proveedor en la familia, con un sello amoroso y comprensivo hacia sus seres queridos, para extender este mismo sentimiento hacia la sociedad.

De igual manera, la educación es primordial para afianzar la autonomía familiar pues, en cierto sentido, garantiza una formación para la vida y el trabajo. El conocimiento es un ingrediente esencial para proyectarse como una persona digna: aprender un arte, una técnica, una tecnología o profesionalizarse, ayuda a pensar con lucidez los problemas prácticos de la vida, sobre la ciencia y la humanización del hombre. Lo que más llama la atención es que es un proceso de alfabetización que abarca toda la vida, para producir emociones y cogniciones que permitan descubrir los secretos de la humanidad y la formación del espíritu científico. La autonomía como propósito intelectual, moral y científico comienza cuando los miembros de la familia aprenden a leer y escribir para descifrar las bondades y las atrocidades de los hombres, para emprender lecturas críticas sociales y políticas, para enseñar a otros cómo desenvolverse en tiempos caóticos, para acceder a categorías y conceptos disciplinares que rompen con la ignorancia, para valerse a sí mismo en la creación de representaciones e imaginarios, que servirán para intervenir en el mundo, en especial, para aprender de la humanidad y ascender en la complejidad del conocimiento. La autonomía forjada en la educación es una pedagogía de la esperanza, porque se piensa en una mentalidad ilustrada para dirimir los problemas de la humanidad con razones morales, artesanales, prácticas, sociales, políticas, técnicas en una sociedad en constante erupción.

Es importante que la familia pueda contar con espacios recreativos y deportivos, actividades culturales y medios para acceder a una educación artística. Esta capacidad secundaria es fundamental porque 
contribuye a una inteligencia emocional sana, para que el individuo emplee el tiempo libre en enaltecer otros talentos relacionados con las inteligencias múltiples que enuncia Howard Gardner (lingüística, musical, espacial, naturalista, matemática, cinética, interpersonal e intrapersonal), con el fin de promover mentes despiertas y estructuradas que transformen asertivamente el mundo. Por ende, la autonomía, en aras de gestar capacidades secundarias, es necesaria para que los integrantes de la familia se aparten de la droga, el vandalismo, la prostitución, la trata de blancas, el consumo de alcohol y otras acciones que demeritan la grandeza de la humanidad. No hay que olvidar que las familias paupérrimas, pobres y marginadas no cuentan con escenarios de vida para canalizar el tiempo libre de los niños, niñas y jóvenes, y evitar que el mal se convierta en un catalizador que afecte la sociedad actual. Estas circunstancias exigen replantear las políticas e invertir recursos económicos para proyectos educativos, deportivos, recreativos y culturales por parte del Estado, la empresa privada y las instituciones educativas, con el fin de formar una sociedad que despliegue sanas emociones acerca de la vida, para cambiar los tiempos caóticos por tiempos de entendimiento y alegría.

Los medios de comunicación, específicamente el internet, se convirtieron en un imperativo de la vida social, porque las redes sociales hicieron de la vida privada, y de la autonomía de los integrantes de la familia un evento público, posibilitando a la mayoría de la población compartir lo que vive en la cotidianidad, sin distinción de clase. Por tal motivo, las tecnologías de la información y la comunicación se constituyeron en una forma de vida que acapara la atención del núcleo familiar para bien o para mal. En otros términos, el internet es un bien cuando encuentra un canal de comunicación para expresar lo que se siente en la miseria, la pobreza y la marginalidad; para expresar los deseos y los anhelos de posicionarse en la vida; la frustración y la derrota ante la inequidad de la sociedad; el estilo de vida de los humildes, de la clase media y pudiente; lo que piensan las multitudes inteligentes, lo que pasa en la localidad y en el mundo global; también cuando hace de la virtualidad un medio y una mediación de aprendizaje. Hoy en día, las redes sociales son tan famosas que la semántica, el lenguaje y el significado de aquellos que no tienen voz adquieren una 
dimensión de parlante para los otros, integrantes de una sociedad de la invisibilidad temporal. Por otra parte, las redes sociales, vistas desde la perspectiva del mal, afectan a la familia cuando la autonomía no está afincada en una moralidad del bien, cuando se impone un ropaje que tapa la identidad de las personas, una fachada que esconde intereses de maldad, o por el auge desbordado de lo erótico y la sexualidad, extrañas formas de comprender e interactuar en el ámbito de lo sentimental y lo afectivo, o cuando se genera la necesidad de presentar la vida privada como si fuera una película en la que desconocidos gozan de las vergüenzas de los demás.

Gardner (2014) sostiene que el papel de las nuevas tecnologías y aplicaciones incide en los jóvenes de la siguiente manera:

Las nuevas tecnologías pueden abrir oportunidades nuevas a la autoexpresión. Sin embargo, vincular demasiado la identidad personal a algunas características de estas tecnologías (y carecer del tiempo, de la oportunidad o de la voluntad de explorar la existencia y las vidas del mundo real) puede dar lugar a una entidad empobrecida. (p. 96)

Esto indica que los medios de comunicación hacen más asequible o más complicado el desarrollo de la autonomía en la familia. Como capacidad secundaria, el Estado, las empresas y las instituciones educativas tradicionales y aquellas que emplean la virtualidad, deben propiciar un espacio de autonomía y emprendimiento en la formación humana, para que la familia se catapulte a un mundo académico, laboral, artesanal o artístico. Por tal razón, los enfoques y currículos tienen que reinventarse con políticas de inclusión, para que los miembros del núcleo familiar puedan participar de las experiencias formales y no formales de la escuela y la universidad. Este es un difícil reto para la sociedad y las instituciones, aunque la tecnología y la virtualidad pueden ser grandes aliadas, pues ayudan a abaratar los costos y disponer de recursos del mundo hipermedial y multimedial en el diseño de proyectos educativos que beneficiarían a los individuos y a los colectivos. Esto con la pretensión de que aprendan a pensar con iniciativa, a amar al otro 
de forma generosa, actuar de forma comprometida y solidaria, evaluar lo que hacen por ellos mismos y lo que hacen los demás para adquirir un pensamiento crítico, a decidir entre las mejores alternativas, a emprender nichos de negocio y proyectar un mundo de posibilidades educativas y productivas para las futuras generaciones.

Del mismo modo, la salud es una capacidad secundaria fundamental para la familia, pues con ella se garantiza el bienestar, que a su vez asegura una sana vida biológica, emocional y cognitiva. Los países que están en vía de desarrollo tienen que invertir en salud. Aquellas familias paupérrimas, pobres, marginadas, o de un nivel medio, que se encuentran generalmente en las periferias de las metrópolis, están en una situación de desventaja porque su servicio médico es muy deficiente, no cuentan con el dinero suficiente para una buena nutrición, ni para cubrir los gastos que demanda la calidad de vida. Este factor es decisivo para contar con una salud sana que respalde el desarrollo humano autónomo, y se debe trabajar en él para que la juventud no incurra en hechos atroces por querer atender las necesidades básicas de sobrevivencia. Cuando un grupo representativo está bien alimentado y goza de buena salud, también cuenta con más posibilidades cerebrales, sociales, culturales y científicas para sentir empatía, afinidad, reciprocidad, liderazgo y motivación para emprender proyectos individuales y comunitarios; esto no quiere decir que una población, al vivir en circunstancias negativas, no posea el potencial cerebral y emocional, sino que las circunstancias y el contexto se pueden convertir en un limitante de oportunidades y de calidad de vida. "En este sentido, la capacidad relacional tiene que ver con la gestión de los estados cerebrales de los demás". (Goleman, 2011, p. 75). Por consiguiente, el estado cerebral de un grupo con seguridad social y bienestar, será muy diferente a aquel que viva en una situación de marginalidad.

También, la participación en política es una capacidad secundaria que debe cultivar la familia. Es decir, es muy importante crear en la familia emociones políticas para saber y actuar en la ciudad con un sentido de responsabilidad de cara al Gobierno, los cuerpos colegiados del legislativo y otras instituciones que forman parte de la experiencia democrática. La familia debe hablar de temas relacionados con la gobernabilidad, para que los futuros ciudadanos puedan participar de 
forma activa sobre ideas e ideologías que marcarán el rumbo de la ciudad y del país. Se debe dar a conocer a los niños, niñas y jóvenes el papel que ha desempeñado Grecia para consolidar las bases de Occidente en torno a la democracia, teniendo como referente la igualdad, la equidad, la libertad y el diálogo argumentativo. Además, la democracia posibilita a los ciudadanos expresarse y hacer gala de la libertad, sin atentar contra la dignidad de los demás. Igualmente, la literatura, el arte, la estética y las nuevas tecnologías son un apoyo estratégico para que los integrantes de la familia asuman de forma sensible el acto de comprometerse con la sociedad a través del liderazgo, que apunte a solucionar los problemas que afectan al colectivo.

La familia tiene que trabajar la capacidad de la política, lo cual requiere reeducarla para que aprenda a conocerla y a tener protagonismo político. La literatura, el arte y las nuevas tecnologías proporcionan experiencias valiosas para tomar conciencia sobre la crueldad, maldad, bondad, generosidad y liderazgo en el quehacer político. Para aprender a participar en la política se tiene que profundizar en la personalidad, humanidad y deshumanización de los políticos y revisar el caso de las sociedades que han experimentado la hegemonía del poder político. Esta capacidad permite gestar emociones y racionalidades para pensar y actuar de un modo más correcto y ético, de acuerdo con la información aprendida e interpretada. También, para este propósito, se debe agregar una lectura del contexto en tiempos caóticos. Son importantes los conocimientos ideales y prácticos que aprende el núcleo familiar acerca de la política, para intervenir de una forma más acertada en la Torre de Babel del mundo político contemporáneo, local y global; ello significa amar la política con un sentido honesto, transparente, ético y sincero.

La familia tiene que enseñar a sus integrantes cómo participar en política. Lo que se escucha en la sociedad es el interés de un grupo de individuos para convertirse en políticos, que luego se apropian de los recursos del Estado, contaminando todo lo que dicen y tocan, deviniendo en depredadores deshonestos que se visten con un ropaje de ética falso, que cubren la verdad con mentiras, tal como se aprecia en el sinnúmero de situaciones que denuncian los medios de comunicación. Es importante trabajar la emoción de la ética política para 
propiciar la mayor transparencia; es decir, la familia tiene que enseñar a los niños, las niñas y los jóvenes que la honestidad paga en la política, porque los recursos económicos no se deben desperdiciar en el afán devorador de la riqueza; por el contrario, se tiene que pensar en la inversión de un presupuesto para la mayoría de la población, que demanda soluciones a una diversidad de necesidades sociales, educativas, científicas, tecnológicas, artísticas, recreativas y de salud, entre otras. A través de la política se puede aportar una serie de soluciones para crear capacidades productivas y de emprendimiento, que se multiplican para moverse en el plano de las necesidades que no implican a un solo individuo, sino al colectivo y a la sociedad.

Por otra parte, la familia tiene que crear capacidades relacionadas con el protagonismo y las emociones políticas, basándose en la capacidad del amor para trasformar la sociedad, a través del diálogo y la escucha. Se deben incentivar capacidades y emociones como la sensibilidad hacia los problemas sociales, la asunción de la libertad como compromiso de quienes llegan a la mayoría de edad, la búsqueda de la paz para ir a la conquista de la convivencia, igualmente, la ponderación de la creatividad hacia proyectos de emprendimiento y el aprendizaje de pensar por sí mismo, para gobernar con una alta autoestima. La autonomía en la familia tiene que hacerse evidente para propiciar emociones y reflexiones cognitivas evaluativas que culminen en acciones concretas, para que sus integrantes se muevan en el ámbito de las relaciones interpersonales, de la comunicación asertiva y del sano entendimiento, para asumir una actitud de apertura y de apoyo recíproco en el otro; se debe incentivar la capacidad de hacer de la ética y la moralidad una forma de vida, la convicción para tomar decisiones creativas que transformen la humanidad, la política, la economía, la producción, la ciencia y la tecnología para conseguir el bien común. Este tipo de protagonismo creará conciencia frente a ideologías políticas dogmáticas y reduccionistas, para detectar en la ética de la relatividad una forma peligrosa de reconfiguración del territorio humano. Este protagonismo debe comprender que las emociones políticas apoyadas en estrategias y dramatúrgicas impiden la participación real del ciudadano en la toma de decisiones coyunturales del país, y la formación de un pensamiento crítico para intervenir en el mundo social y 
político y discernir sobre los razonamientos contaminantes que afecten el desarrollo de la humanidad.

La familia es el punto nuclear en la gestación de un protagonismo de las emociones políticas, es ahí donde se siembra la semilla para aprender a participar en los problemas que experimenta la sociedad contemporánea. Esto significa que el contacto parte de una sensibilización en las letras, el arte, la estética, los medios de comunicación y la tecnología, para proporcionar insumos necesarios para comprender los grandes problemas políticos que experimentan las sociedades locales y globales, que se tienen que confrontar con el ideario ilustrado de las primeras civilizaciones, como los griegos, quienes sentaron las bases del quehacer político en el mundo occidental. Sin embargo, las emociones que se perciben en la familia sobre la política giran en torno a gobernantes deshonestos, corruptos, capitalistas, dueños de gran parte de la infraestructura del país, depredadores de una economía casera y responsables de una pésima gestión para liderar procesos políticos. Esto debe convertirse en un aprendizaje sobre el papel del futuro ciudadano, aprendizaje que implica formar un pensamiento crítico para no caer en las redes pragmáticas instrumentales de los políticos, donde el ideario democrático se compra por atender las necesidades inmediatas, sin pensar en las consecuencias que acarrea para las futuras generaciones.

La sociedad actual atraviesa por una crisis a causa de un mundo que perdió la sensibilidad ante la miseria humana, los desplazados (que intentan sobrevivir en tierras ajenas a la nativa), la guerra que desgarra y mata a los miembros de la familia, la muerte que se encuentra en cada esquina, el vandalismo que azota a una sociedad trabajadora, la drogadicción que se extiende como veneno que contamina a jóvenes y adultos, la prostitución como medio para esclavizar a la población más débil y la violencia que no cesa a nivel local y global. Es necesario crear emociones sobre los problemas y dilemas que experimenta el hombre de la periferia de las ciudades y del campo (quien debe tener un caparazón a prueba de sufrimiento, dolor y muerte) para propiciar la compasión, la empatía, la entrega, el servicio al otro, la caridad, la misericordia y la capacidad de amar con justicia y equidad. En suma: 
Si queremos compasión cívica, tendremos que entender qué es lo que amenaza. Todo nuestro proyecto parte de una desgraciada realidad: las personas son proclives a la estrechez y a la avaricia a la hora de formarse las simpatías, lo que las hace reacias a apoyar proyectos orientados al bien común si estos exigen de ellas algún sacrificio. (Nussbaum, 2014, p. 379)

La familia tiene que aprender a cultivar la sensibilidad hacia la humanidad, lo que significa realizar acciones tangibles para el bien común. La sensibilidad hacia el otro se percibe cuando se entienden las situaciones de desgracia, las pésimas decisiones relacionadas con el proyecto de vida personal, los errores que se cometen en términos de justicia y equidad, cuando se perdona y se tolera las imperfecciones del otro, cuando se trabaja más en las virtudes y las fortalezas. Aunque es la emoción del amor, como piedra angular, la que prima y sustenta las otras emociones. Es decir, sin amor, no hay perdón, ni capacidad de escucha o diálogo; sin él no hay posibilidad de asumir la imperfección como el grado máximo para aprender a ser más virtuosos, ni de servir sin esperar recompensa, no podríamos corregir amorosamente a los demás, ni dejar la envidia y la codicia por la riqueza; únicamente es posible transformar la familia y el mundo con la gracia copiosa del amor. Por consiguiente,

El amor es la emoción que constituye las acciones de aceptar al otro como un legítimo otro en la convivencia; por lo tanto, amar es abrir un espacio de interacciones recurrentes con el otro en el que su presencia es legítima sin exigencias. (Maturana, 2001, p. 46)

Por tanto, el amor como una capacidad protagónica se ha perdido en la sociedad actual a causa de los afanes de la vida, del trabajo, de la preocupación de tener y poseer riqueza, del impacto de los medios de comunicación al ofrecer emociones y razones relativas, a causa de experimentar el juego del amor físico con las respectivas consecuencias de embarazos no deseados, del interés en una sexualidad desenfrenada, del aumento de la prole en medio de la pobreza 
y de la ausencia del sentido de la responsabilidad para asumir los compromisos que impone la vida misma. Toda esta carga de situaciones altera la verdadera razón del amor, que radica en el servicio y entrega a la otra persona para que tenga compasión hacia el otro. Hoy de cierta manera, se percibe el núcleo familiar como un dinosaurio que cumplió con la supervivencia de la especie humana, para dar paso a ideas que revaloran los problemas de género como algo atrayente que puede suplir la esencia de la familia y de los contrarios, desembocando en un ideario en el que todo vale, según lo que el hombre y la mujer quieran hacer en el mundo secularizado, con razones o sin razones; ocultan la verdad con el ropaje de mentira que caracteriza a una sociedad caótica, ausente de valores fundamentales que nutran el horizonte de la humanidad. Entonces, "lo más probable es que todos esos amores que inducen un comportamiento bueno comparten ciertos rasgos: la consideración del objeto de ese amor como un fin en sí mismo, más que como un mero instrumento" (Nussbaum, 2014, p. 462).

El amor cultiva la humanidad en la familia porque allí se vive de forma incondicional el respeto y el compromiso hacia la dignidad de la persona. En otras palabras, únicamente en la familia se aprenden las caricias, las primeras letras y el laberinto del lenguaje, para luego formar parte del activo social; en la familia se puede dar el amor en su máxima pureza y fidelidad, la lealtad, las luchas esporádicas quizás, y el perdón, también, el sacrificio para promover en los integrantes del núcleo familiar el proyecto de vida personal. En la familia, las lágrimas se secan con la felicidad de la comprensión amorosa y el diálogo; el conflicto se autorregula con la misericordia del amor, la máxima expresión de interacción y servicio para perseguir la verdad, porque el amor le dice a las emociones y a la razón que la verdad tiene que prevalecer para impartir justicia y equidad. Lo hermoso del amor es que se percibe como un ideal que impera en la realidad, cuando la humanidad reclama, no la riqueza y el poder, sino la grandeza del corazón para gobernar con el bien común, como única medida que garantiza la dignidad de la persona, más que la razón. Por consiguiente, "los ideales que imaginamos están anclados en la realidad del cuerpo y la psicología humanos, por lo que simplemente reflejan el hecho innegable de que 
los seres humanos quieren progreso, belleza y bondad" (Nussbaum, 2014, p. 465).

Por otra parte, la capacidad protagónica del diálogo y la escucha es determinante para cultivar la humanidad en la familia, en cuanto significa humildad y reconocimiento a la intervención dialógica de la otra persona. La falla de la comunicación en el núcleo familiar obedece a la ausencia de la fluidez en el diálogo y la falta de escucha para entender los problemas que vive cada miembro. Se constituye, entonces, de cierta manera, en una comunicación de sordos que termina por trasladar la confianza a individuos y redes sociales que, aparentemente, actúan como pararrayos, y que pretenden granjearse la confianza para contaminar los intereses del mundo, lo que termina desvinculando a los integrantes de la familia porque aparecen otros actores con máscaras, que aluden a situaciones de inmoralidad y amoralidad, y que terminan por hundir el tejido amoroso, afectivo, social, cognitivo, emocional y racional. El diálogo es una comunicación de biografías y rostros, que se articulan en un lenguaje de emociones, racionalidades e irracionalidades. En la familia, todos tienen algo que decirle al otro sobre algo que sucede en el mundo, en especial, acerca de cómo se sienten en relaciones de dominio paternal y maternal, acerca de la relación con iguales, de inquietudes e interrogantes que plantean los medios de comunicación, de la forma como personas externas tergiversan el sentido amoroso de la vida, de cómo la riqueza y la droga se apropian de la voluntad del otro, de cómo la violencia y la muerte campea en el hogar, de cómo el mundo líquido genera sunamis que devastan el núcleo familiar y la sociedad que pierde el horizonte del humanismo. En consecuencia, el mundo del internet limitó aspectos del individuo y la familia, la "privacidad, intimidad, anonimato, derecho al secreto quedan fueran de las premisas de la Sociedad de Consumidores o son rutinariamente confiscados por los agentes de seguridad a la entrada" (Bauman, 2015 , p. 41). Lo anterior indica que la familia y la sociedad forman parte del juego del consumo de internet, lo que altera la esencia del diálogo y la escucha, pues aparece en escena la reencarnación de nuevas promesas emocionales y racionales que alteran la naturaleza de los valores de la familia. 
El ejercicio de diálogo y de escucha en la familia tiene que ver con las argumentaciones y contraargumentaciones acerca de lo que sucede en el mundo cotidiano y práctico. Esto quiere decir que las cosas más elementales de la vida son motivo de diálogo: las preguntas y preguntas inacabadas que formulan los niños y niñas, los intereses relacionados con los hermanos, los amigos, lo que sucede en el hogar en cuanto a discordias, peleas, anhelos, aspiraciones, pobreza y riqueza, estudio, trabajo, hambre, miseria, drogadicción, pésimas amistades; es decir, todo lo que sucede en el micromundo de la familia es el reflejo de los grandes problemas de la sociedad contemporánea. Los adultos no están dispuestos a escuchar las demandas de los menores de edad, y se pierde un espacio de argumentación que puede ser útil para entender las intencionalidades que afloran en los discursos sobre los acontecimientos y los problemas del hogar. Así se da paso a la pérdida de la comunicación, puerta de entrada de la contaminación del mundo. Entonces, de alguna manera, no es la familia la que nutre el mundo, sino la sociedad que carga con las bondades y las plagas para invadir y conquistar el núcleo familiar, sociedad en la que el caos y la confusión se erigen como una bandera de irracionalidad y destrucción de las buenas prácticas amorosas. Por dar un ejemplo,

un estudio reciente de la Kaiser Family Foundation descubrió que la gente joven de edades comprendidas entre los 8 y 18 años pasa, en estos momentos, más de siete horas y media al día con los teléfonos, ordenares, televisiones y otros artefactos electrónicos. (Bauman, 2013, pp. 64-65)

Por otra parte, uno de los grandes retos que tiene la familia es el buen ejercicio de la libertad en la búsqueda del bien común. El concepto de libertad está mal interpretado cuando se asume como dar rienda suelta a las malas emociones y pasiones que demanda una sociedad fuera de control, para perseguir el poder, la riqueza, comprar el amor, para anhelar el ascenso, la lujuria, la codicia, la corrupción, el vandalismo, etc. El fenómeno de la contaminación social ha minado la libertad en la familia, lo cual genera caos, confusión, desorden, disfuncionalidad y 
destrucción de los valores que cimientan la libertad con conciencia en el ámbito de la ética y la moralidad. Entonces, existe una avalancha de circunstancias negativas que atentan contra la dignidad de la persona, que se presentan con un ropaje ético que carece de honestidad y transparencia. Los medios de comunicación bombardean la conciencia de los miembros de la familia, quienes asumen lo que hacen otros como la esencia de la libertad, que terminan por imitar la barbarie del mundo actual, pasando el lindero que impone la libertad del otro. Por ende, "lo que cabe exigir es que cada persona limite su libertad en función de la libertad de los demás" (Nussbaum, 2007, p. 47).

Es aterrador ver la inteligencia emocional de las familias que viven en zonas marginadas, de aquella juventud descarriada que percibe la minoría de edad como una licencia para robar, matar, generar violencia, para que la muerte camine en las ciudades, por carecer de un proyecto de vida que asegure sustento, casa, educación y empleo. Entonces, la garantía de la libertad se encuentra en peligro, porque el irrespeto a la vida implica cruzar un lindero minado de malas emociones que se alimentan de desigualdad y pobreza, por ausencia de oportunidades políticas y económicas, de ascenso social, de educación, de trabajo, emprendimiento, por la imposibilidad de formar parte de un proyecto cultural que cambie la mentalidad de los jóvenes. Por tanto, la familia requiere que el Estado, la sociedad y las instituciones, con voluntad política emprendan un proyecto de emociones (que vincule gobernantes, capitalistas, emprendedores, científicos, intelectuales y ciudadanos) que implique inversiones éticas, morales, económicas, sociales y culturales. El gran proyecto educativo exige la siembra de buenas emociones que exalten la libertad, impregnada de amor, que inculquen el respeto de los otros, que valoren la vida ante la muerte, el compromiso y el servicio al otro; exige la gestación de una cultura que arremeta contra la relatividad ética y moral y, sobre todo, una cruzada económica y cultural que brinde posibilidades de mejorar la calidad de vida del individuo y del colectivo.

Es importante cultivar en la familia el amor ideal, hacer frente a una realidad violenta en la que impera el descarte del amor, en la que se afecta el ejercicio de la libertad recurriendo a acciones que atentan contra la libertad del otro. En otros términos, si el amor impera en los sentidos de la familia, la libertad cumplirá el rol de testificar la bondad 
de la humanidad, porque el amor genera respeto hacia la dignidad de la persona, y temor para no atentar contra la vida, para mantenerse en el marco de una ética y una moralidad que concibe al individuo como un regalo sagrado que interactúa con otros congéneres sagrados. Por tal motivo, se requiere unir esfuerzos para pregonar un amor ideal de entendimiento, convivencia, diálogo y servicio en medio de la riqueza, la pobreza, la miseria, la hambruna, la enfermedad, la opulencia, la disfuncionalidad y la negación de la otredad. El amor ideal arrastra las emociones y la racionalidad para corregir aquello que esta estropeado, para convertirlo en un amor ardiente que pula lo burdo, lo lime, para que brille con luz propia. Es decir, "cuando amamos a personas, queremos ser buenos para ellas y eso significa normalmente ser mejores de lo que somos a veces, o incluso habitualmente" (Nussbaum, 2014, p. 45).

\section{Conclusiones}

La sociedad pasa por un periodo caótico y sufre las grandes transformaciones de la ciencia y la tecnología; la globalización choca con populismos continentales y regionales; la economía, desbordante, demanda el uso abusivo de los recursos naturales y el medio ambiente; la violencia y la muerte hacen parte de arraigadas ideologías religiosas y políticas; los medios de comunicación sacralizan lo banal y lo pasajero en medio de racionalidades secularizadas que compiten y riñen con el humanismo, la ética y la moral. Estos fenómenos tan complejos inciden en la familia, que se encuentra bombardeada en una Torre de Babel, caminando por un laberinto, con más desaciertos que aciertos, lo cual obliga a plantear la necesidad de generar autonomía para crear capacidades y emociones en su interior, valores que se fundamentan en el amor, y a reclamar acciones por parte del Estado, las instituciones públicas y privadas, la sociedad y el ciudadano como tal. Se necesita pensar el quehacer de la familia para las futuras generaciones, pero no como algo aislado, sino como la célula que nutre de calidad de vida a la humanidad. De ahí que la creación de capacidades y emociones en la familia requiera de una política que se involucre con proyectos 
educativos y económicos de orden intelectual, disciplinar, productivo, científico, social, cultural, artístico, agrícola... O sea que la capacidad del amor se apoya en el desarrollo de las capacidades centrales, para atender las necesidades básicas y secundarias, para que el hombre contemporáneo se pueda proyectar en términos de una buena vida, que conduzca a la felicidad.

Los desafíos de la sociedad contemporánea han incidido en la familia, cambiando conductas, comportamientos, creencias, actitudes y valores, creando un colectivo afanado por el poder, la riqueza, la ciencia y la tecnología. La relatividad ética y moral permea la política, la religión, la cultura, el arte y los estilos de vida, según los intereses y circunstancias de múltiples subjetividades. Este fenómeno cognitivo y moral, sustentado en la secularización, ha impactado en la familia a través de nuevos hábitos que emergen del mercado, la moda, los placeres, el capitalismo y el neoliberalismo, y todo lo que proporciona el mundo de la sociedad líquida. Entonces, desde la educación se tienen que crear capacidades y emociones que redimensionen el amor como servicio, como entrega generosa, con un alto sentido de responsabilidad, del bien común y del diálogo, para superar los problemas cotidianos, perdonar y perdonar los actos atroces, amar y amar a los miembros de la familia para que no se pierdan en las explosiones sensitivas de las ofertas del mundo (como el sexo, la droga, la prostitución, la trata de blancas, pérdida de autoestima y la falta de compasión hacia los demás).

La cultura es un factor decisivo para el desarrollo de la autonomía de la familia, ya que aparece como un espacio social y simbólico, que se interpreta según el contexto y las circunstancias que viva cada integrante en el interior del colectivo. También, un espacio de pobreza y marginalidad determina los espacios simbólicos y semióticos. Además, sin disponer del capital relacionado con la producción, el emprendimiento, la cultura, la ciencia y la tecnología, por mencionar algunos aspectos, es muy difícil que la autonomía pueda crear capacidades y emociones de bienestar y de felicidad, especialmente cuando se carece de los bienes básicos necesarios, porque son la punta de lanza para la búsqueda de la igualdad, la equidad, la justicia, la convivencia y la vida productiva. 


\section{Referencias bibliográficas}

Aebli, H. (1998). Factores de la enseñanza que favorecen el aprendizaje autónomo. España: Narcea.

Bauman, Z. (2005). Ética posmoderna. Buenos Aires: Siglo Veintiuno Editores.

Bauman, Z. (2013). Sobre la educación en un mundo líquido. Conversaciones con Ricardo Mazzeo. Madrid: Espasa Libros, S. L. U.

Bauman, Z. (2015). Ceguera moral. La pérdida de sensibilidad en la modernidad líquida. Barcelona: Paidós.

Bonilla Castro, E. y Rodríguez Sehk, P. (1997). Más allá del dilema de los métodos. La investigación en ciencias sociales (2. ${ }^{a}$ ed.). Santa Fe de Bogotá: Norma.

Bourdieu, P. (2007). Razones prácticas sobre la teoría de la acción. España: Anagrama.

Calvo, G. (1995). La familia en Colombia un estado del arte de la investigación. (Vol. 1). Santa Fe de Bogotá: Instituto Colombiano de Bienestar Familiar.

Gardner, H. y Katie, D. (2014). La generación APP. Cómo los jóvenes gestionan su identidad, su privacidad y su imaginación en el mundo digital. Barcelona: Paidós.

Goleman, D. (2012). El cerebro y la inteligencia emocional: nuevos descubrimientos. Barcelona: Ediciones.

Geertz, C. (2006). La interpretación de las culturas. España: Gedisa.

González L., J. y Marquínez, G. (1999). Valores éticos para la convivencia. Santa Fe de Bogotá: Códice.

Maturana, H. (2001). Emociones y lenguaje en educación y política. Santiago de Chile: Dolmer Ensayo.

Maturana, H. y Verden, Z. G. (2007). Amor y juego. Fundamentos olvidados de lo humano. Chile: J. C. Sáez.

Nussbaum, M. C. (2007). Las fronteras de la justicia. Conmiseraciones sobre la exclusión. España, Barcelona: Paidós Ibérica.

Nussbaum, M. C. (2008). Libertad de conciencia. Contra los fanatismos. México D. F.: Tusquets.

Nussbaum, M. C. (2008). Paisajes del pensamiento. La inteligencia de las emociones. Barcelona: Paidós Ibérica. 
Nussbaum, M. C. (2011). Sin fines de lucro. Por qué la democracia necesita de las humanidades. Bogotá: Panamericana.

Nussbaum, M. C. (2012). Crear capacidades. Propuesta para el desarrollo humano. Barcelona: Paidós.

Nussbaum, M. C. (2014). Emociones politicas ¿̇por qué el amor es importante para la justicia? España: Espasa Libros.

Pachón, X. (2007). La familia en Colombia a lo largo del siglo xx. Recuperado de http://www.bdigital.unal.edu.co/1363/13/12CAPI11.pdf?

Rovichaux. D. (Ed). (2007). Familia y diversidad en América Latina: estudios de casos. Buenos Aires: Clacso.

Sastoque, L. F. (2001). Fundamentos teológicos de Moral Cristiana. Bogotá: Biblioteca Dominicana del Santuario.

Savater, F. (2008). Ética como amor propio. Barcelona: Ariel.

Solís, T. A. (diciembre, 2004). La familia y cultura: cambios socio-culturales en el siglo xxi. Revista de Educación, Cultura y Sociedad, 7(2), 103-108.

Unicef - UDELAR. Nuevas formas de familia. Perspectivas nacionales e internacionales. Recuperado de http://files.unicef.org/uruguay/spanish/libro_familia.pdf 
